\title{
ASPECTOS LEGALES DE LAS REDES SOCIALES
}

AUTORES: Albert Agustinoy Guilayn y Jorge Monclús Ruiz

Edición: Enero 2016

ISBN: 978-84-9090-105-2

Colección: Práctica Jurídica; BOSCH

Las redes sociales se han convertido en una herramienta esencial de comunicación personal, profesional o comercial. Estos usos han dado lugar igualmente a un número creciente de conflictos legales que han requerido un esfuerzo interpretativo e incluso, en algunos casos, la revisión de la normativa en cuestión.

Esta obra analiza los desarrollos legales e interpretativos que este fenómeno ha propiciado a fin de encontrar soluciones legales a problemas derivados del masivo uso de las redes sociales. A tal efecto, se sistematizan y examinan los criterios interpretativos aplicados por la jurisprudencia española y comunitaria en los ámbitos legales más relevantes respecto a estos nuevos sistemas de comunicación.

Así, se estudia el enfoque que la jurisprudencia ha establecido respecto a este tipo de conflictos en áreas tales como la normativa de los servicios de la sociedad de la información y del comercio electrónico, la protección de datos de carácter personal, la propiedad industrial e intelectual, el derecho penal y los derechos de la personalidad, el derecho laboral y la publicidad.

La obra, que está dividida en cinco bloques, incluye un amplio estudio doctrinal introductorio en el que se abordan temas de sumo interés como su funcionamiento, la normativa de servicios de la sociedad de la información, la protección de datos, la 
propiedad intelectual e industrial, la protección penal y civil de los derechos personalísimos y su influencia en el entorno laboral.

Cuenta este trabajo con un apartado que se dedica a la problemática jurisprudencial, así como un bloque de esquemas procesales y formularios, para finalizar con la normativa reguladora. 